\title{
School Counselors' Ethical Considerations in Prevention and Counseling of Substance Abuse
}

\section{물질남용 예방과 상담에서 학교상담자의 윤리적 고려}

\author{
Hyundong Son ${ }^{1}$ \\ 손현동1 \\ ${ }^{1}$ Professor, Department of Education, Gwangju National University of Education, Korea, \\ chamcoun@gnue.ac.kr
}

\begin{abstract}
The purpose of this study is to review the literatures on the ethical factors that school counselors should consider when preventing and counseling students' substance abuse. As a result, ethical factors to be considered were found in the areas of prevention, assessment, and counseling. In each area, the important ethical considerations were identified and discussed. The common ethical considerations were related to confidentiality and its breaches. Confidentiality starts to be considered from prevention activities. And in counseling activities, considerations on confidentiality breach and responsibilities for parents are included. This study is meaningful in that it has clarified and discussed the ethical factors that should be considered by school counselors in a situation where there are no established ethical regulations or provisions of the law in relation to substance abuse.
\end{abstract}

Keywords: School counselor, counseling ethics, substance abuse prevention, substance abuse counseling, confidentiality

요약: 이 연구의 목적은 학교상담자들이 물질 남용에 대한 예방과 상담 시 고려해야 할 윤리적 요소가 무엇인지를 고찰하는 것이다. 그 결과 고려되어야 할 윤리적 요소는 예방, 사정, 상담 장면에서 찾을 수 있었다. 각 장면에서 중요한 윤리적 고려 요소가 무엇인지 밝혔으며, 공통적으로 중요한 윤리적 고려는 비밀보장과 그 예외와 관련된 것이었다. 비밀보장에 대한 고려는 예방활동에서부터 시작되어야 하며 상담 활동 시에는 비밀보장의 예외, 그리고 부모에 대한 책임까지도 고려해야 한다. 이 연구는 아직까지 물질 남용과 관련해 학교상담자들이 지켜야 할 윤리규정이나 법 조항이 정비되지 않은 상황에서 학교상담자들이 고려해야 할 윤리적 요소가 무엇인지 밝히고 논의하였다는 점에서 의미가 있다.

핵심어: 학교상담자, 상담 윤리, 물질 남용 예방, 물질 남용 상담, 비밀보장

\section{1. 서론}

물질남용(substance abuse)은 신체적으로 해가 되고 하나 이상의 영역(예: 가족, 학교,

Received: December 22, 2020; $1^{\text {st }}$ Review Result: February 3, 2021; $2^{\text {nd }}$ Review Result: March 25, 2021 Accepted: April 30, 2021 
또래관계 등)에서 분명하게 부정적인 결과를 가져옴에도 불구하고 감정, 행동, 인식에 인위적으로 변화를 일으키고자 향정신성 물질을 지속적으로 사용하는 것을 말한다[1][2]. 물질 남용은 신체, 정서, 인지, 문제 행동 증가의 어려움을 초래하는 것으로 알려져 있다[3]. 특히 청소년기에 물질을 사용하거나 남용하게 되면 성인기에 물질 중독으로 빠질 가능성이 매우 많기 때문이다[4].

물질남용은 물질에 대한 의존상태를 심화시켜 내성과 금단 증상을 겪게 하고, 결국 청소년들의 삶에 대한 만족도가 낮아지게 하며 자살의 위험도 높인다[5]. 또한 물질 남용은 범죄로 인한 사회적 비용의 증가, 중독에 의한 질병 치료 비용 등 막대한 경제적 손실을 초래한다[6]. 이런 이유로 청소년들을 대상으로 한 물질 남용에 대한 예방과 상담이 중요하다.

초·중·고등학교에서 근무하는 학교상담자들이 물질 남용에 대한 예방과 상담에 있어서 반드시 고려해야 하는 것이 학교상담자 윤리이다. 이는 내담 학생과 학교상담자 자신을 보호할 뿐만 아니라 상담을 진행하는 행동 지침이 되며 전문직의 지위를 유지시키는 데 이바지한다[7]. 그러나 학교상담자들은 윤리적 갈등에 자주 직면하게 된다[8]. 왜냐하면 학교상담자들의 주요 서비스 대상이 미성년자이기 때문에 부모의 알 권리를 보장해야 할 필요도 있으며, 학생들의 학교 내 성공을 위해 교사 또는 행정가의 협력도 중요하기 때문이다[9]. 그래서 학교상담자들은 '비밀보장과 그 한계', '비밀보장과 부모의 권리', '내담학생의 자율성 보장', '동료 교사와 관리자로부터의 상담내용 공개 요청' 등에서 갈등을 경험하고 있는 것으로 밝혀진 바 있다[7].

물질남용 예방과 상담에서는 이런 영역의 갈등뿐 아니라 법 규정에 저촉되지 않아야 하는 갈등이 더해진다. 예를 들어 상담 중에 학생이 자신이 학교에서 환각제를 팔고 있다고 털어놓았을 때 학교상담자는 어떻게 대처해야 할까? 경찰관이 찾아와서 학교상담자에게 학생이 환각제와 관련한 언급을 했는지에 대해 묻는다면 어떻게 대처할 것인가? 이런 경우 학교상담자는 일반적인 학교상담자 윤리 강령 이외에 법 규정도 고려해야 할 것이다. 미국에서는 중독전문가협회(National Association for Addiction Professionals, NAADAC)[10]에서 윤리 실천 기준을 밝히고 있으며, 연방법(Drug Abuse Office and Treatment Act)에 약물환자의 기록에 대한 비밀보장 관련 법규들을 상세하게 기술하고 있으나 아직까지 우리나라에서는 학교상담자가 고려해야 할 물질남용과 관련된 윤리규정이나 법적인 근거를 찾아보기 어렵다. 또한 학교상담자들이 고려해야 할 물질남용과 관련된 윤리적 이슈에 대한 선행연구도 아직까지 이루어지지 않았다. 이에 물질 남용 학생 예방과 상담에서 학교상담자들이 고려해야 할 윤리적 문제는 무엇이 있으며 어떻게 해결하는 것이 효율적일 지에 대해 고찰할 필요성이 있다. 학교상담자가 물질 남용과 관련되어 주로 하게 되는 활동은 예방활동, 초기 발견과 상담 개입, 의뢰 등이라 할 수 있다. 이에 본 연구에서는 학교상담자가 물질 남용에 대한 예방 활동과 상담, 그리고 의뢰 시 고려해야 할 윤리적 문제들에 대해 논의하고자 한다. 


\section{2. 예방}

\section{1 물질 남용에 대한 학교상담자의 예방 활동}

물질 남용과 관련해 가장 좋은 개입은 예방이라 할 수 있다[11]. 왜냐하면 대다수의 청 소년들이 아직 물질을 사용한 경험이 없기 때문이다. 이런 예방 접근은 청소년들의 물질 에 대한 지식을 증가시켜서 물질에 대한 건전한 태도를 갖도록 하며, 물질 사용 가능성 을 낮추기 위한 것으로, 이런 예방 활동은 대상에 따라 크게 세 가지 형태로 나누어 볼 수 있다.

첫 번째는 일반 학생이나 물질 남용 고위험군 학생들을 대상으로 한 일차적인 예방 교 육이다. 일반학생들에게는 물질 사용에 뒤따르는 위험성에 대해 교육하고, 환각물질 등의 권유 시 거절하는 자기주장 훈련을 시킴으로써 물질 사용 시작을 미연에 방지하는 것이 다.

두 번째는 부모, 친척, 친구 등 주변 인물들이 물질이나 마약류 중독이거나 주변 환경 이 물질 유혹이 많은 물질 남용과 중독에 빠질 위험성이 큰 학생들을 미리 선별하고 이 들에게 예방교육을 시키는 것이다. 부모의 물질 사용과 가족 환경은 청소년의 물질 사용 여부에 대한 주요한 예측 지표이다. 이를 활용한 약물사용 고위험군 선별을 위한 도구도 개발되어 있다. 국내에서도 청소년들의 생활 주변 6개 부분에서 각각 10-12 정도의 70가 지 질문을 던져 약물을 사용했거나 사용할 가능성이 많은 청소년들을 찾아내는 '약물사 용 고위험군 선별 검사표, [12]를 개발한 바 있다.

세 번째는 물질 남용으로 인해 문제를 겪고 있는 학생을 최대한 빨리 밝혀내고, 이렇게 조기에 밝혀낸 학생들에게 개인상담이나 집단상담 등의 서비스를 제공함으로써 물질 남용이나 중독 상태로 진행되지 않도록 하는 이차적인 예방이다. 학교상담자와 담임교사가 물질 남용 의심 학생을 선별하는 데 있어 '십대들의 약물 남용 신호' [13]를 참고할 수 있을 것이다.

\section{2 물질 남용 예방 활동에서 학교상담자의 윤리적 고려}

물질 남용 예방 교육 과정에서 학교상담자가 고려해야 할 윤리적·법적인 측면에는 어떤 것들이 있을까? 일반학생이나 물질남용 고위험군 학생들에게 예방교육을 시키는 데 있어서는 다수를 대상으로 교육적 차원에서 예방 교육이 이루어지기 때문에 윤리적이나 법적인 문제의 소지는 거의 없다 할 수 있다. 예를 들어 학교상담자가 학교에서 알콜과 물질에 대해 교실에서 교육했다. 학교상담자는 이 수업을 진행했을 뿐 이와 관련해서 학생들을 상담하거나 공식적인 사정, 또는 의뢰를 하지는 않았다. 다만 학생들이 수업 중 또는 수업 후에 그와 관련된 내용에 관심을 가지고 있거나 고민이 있는 학생들에게는 그 고민을 들은 후 지지해 주거나 치료를 받도록 충고해 주곤 했다. 이런 경우 학교상담자는 수업 중에 고민을 토로한 학생의 사적 정보가 누설되지 않도록 노력해야 하지만 비밀 보장의 범위는 진단, 치료, 의뢰에 대한 것으로 제한해서 보는 것이 필요하기 때문에[14] 교실 수업 장면에서 벌어지는 일들에 대해서 법으로 규제되지 않는다는 것이다. 
그렇다면 물질 사용으로 문제를 겪고 있는 학생을 찾아내는 과정에서도 법적으로나 비밀보장과 관련된 윤리적 문제가 없을까? 물질 남용 학생을 찾아내기 위해선 학교상담자가 담임교사와 교과 교사들이 적극적으로 참여할 수 있도록 독려해야 하기 때문에 개인의 사생활 정보가 침해될 가능성이 있다. 그러나 물질 남용 의심 징후를 보이고 실제로 물질을 남용하고 있는지 밝히는 과정에서 학교관리자나 담임, 교과 교사, 그리고 그 외의 학생을 지원할 수 있는 사람들과 그 학생에 대해 논의하는 수준에서는 학생의 사생활 보호권을 침해한다고 보기는 어렵다. 왜냐하면 물질 오용과 관련된 비밀보장의 핵심은 그 학생이 물질을 오용하고 있거나 중독된 사실이 타인에게 알려지지 않도록 하는 것인데, 아직까지 정확하게 그 학생에 대한 물질 사용에 대한 평가가 이루어진 것도 그리고 학교상담자로부터 아직 본격적인 상담 서비스를 받은 것도 아니기 때문이다. 즉 학생이 정확하게 사정(assessment) 절차를 신청하거나 사정평가가 시작하기 전까지는 특정 학생이 물질 문제를 가졌는지 알 수 없기 때문에 비밀 보장의 의무를 가진다고 할 수 없다고 볼 수 있다.

학교상담자들이 물질 남용과 관련된 예방 집단상담 프로그램을 할 때 이 학생들의 참여 여부와 관련된 비밀 보장은 어떻게 해야 할 것인가? 프로그램 참여자 명단에 대해 마찬가지로 학교상담자가 비밀을 엄수해야 하는 부분은 특정 학생이 물질 사용자라는 사실을 밝히는 것이다. 그렇기 때문에 만약 물질 남용 프로그램과 더불어 다양한 프로그램을 하고 있는 학교라면, 특정 프로그램에 어떤 학생이 참여했다고 해서 그 학생이 반드시 물질을 남용하고 있다는 것을 나타내는 것은 아니기 때문에 프로그램 참여 명단을 밝히는 것이 비밀보장의 의무를 지키지 못했다고 말하기 어렵다. 그러나 만약 그 학교에서 물질 문제와 관련된 프로그램만 한다면 이 프로그램에 참여한 여부까지도 비밀이 유지되어야 할 것이다. 왜냐하면 이 프로그램에 참여했다는 정보만으로도 특정 학생이 물질 상태에 대해 평가를 받고, 상담도 받고, 또 그 프로그램에 의뢰됐다는 것을 나타내며, 이것은 다시 그 학생이 물질 문제를 가지고 있다는 것을 드러내기 때문이다.

\section{3. 사정 (assessment)}

학생의 물질 사용이나 남용에 대한 사실이 밝혀지면 그 학생에 대한 종합적인 평가가 필요하다[15]. 이 평가는 학생의 물질과 관련된 문제의 심각성을 판정하기 위한 것이다.

학생의 물질남용에 대한 사정과 관련해 고려해야 할 윤리적 요소는 전문적 역량과 비 밀보장에 대한 의무이다. 우선 물질 남용에 대한 사정은 훈련을 받은 전문가가 해야 한 다. 만약 학교상담자가 물질 남용 평가에 대한 전문성이 없다면 외부 기관의 전문가에게 의뢰해야 한다. 다음으로 학생의 물질 남용에 대한 공식적인 평가가 시작되면 학교상담 자는 비밀보장의 의무를 가지게 된다[15]. 만약 학생이 물질 남용 관련 서비스에 대해 문 의를 하거나 그런 서비스가 자신에게 필요한지를 결정하기 위해 검사를 받았다면, 그 학 생에 대한 정보도 공개해선 안 된다. 사정에 대한 약속을 잡는 시점부터 신상정보에 대 해 비밀보장 책임이 있다고 할 수 있다. 


\section{4. 상담}

\section{1 전문적 역량(Competency)과 관련된 윤리적 고려}

일반적으로 물질사용 남용과 관련해 학교에서의 개입은 물질 남용에 대한 교육, 자기주장훈련, 의사결정 전략, 또래 관계 등의 예방적인 부분에 초점을 두고 있다 [16]. 그러나 만약 물질 남용 초기 단계에 있는 학생들이 외부 기관에서 치료를 받을 수 없는 경우, 학교상담자가 직접 개입할 필요가 있다. 그러나 이 경우라도 학교상담자는 물질 중독에 대한 훈련을 받은 경우에 한정되다.

\section{2 비밀보장과 관련된 윤리적 고려}

비밀보장은 신뢰를 바탕으로 한 상담관계를 맺는데 초석의 역할을 한다. 그러나 미국 상담자 협회(American Counseling Association)에서 2002-2003년에 한 윤리 자문 중 50\% 이 상이 비밀보장과 관련된 내용이었다는 점에서[17] 비밀보장은 학교상담자들을 포함한 모 든 상담자에게 상담 실제에 있어 가장 윤리적인 문제를 유발시키는 것이라 할 수 있다. 또한 미국 학교상담자협회(American School Counselors Association)에서 발간하는 학술지에서 학교상담자들의 윤리와 관련된 논문 중 비밀보장과 관련된 논문이 가장 많았던 점에서도 학교상담자들에게 비밀보장 관련된 문제는 매우 복잡하다는 것을 알 수 있다.

물질 남용 문제를 가진 사람들에게는 비밀보장이 그 무엇보다 중요하다. 왜냐하면 물 질 남용 상담 프로그램에 참여하는 것은 불법행위를 했다는 것을 인정하는 것일 수 있으 므로 비밀보장이 되지 않으면 물질남용 상담에 참여하기 꺼려할 것이기 때문이다. 그래 서 미국의 경우에는 연방규정으로 연방정부자금을 지원받는 사람이나 조직은 약물 치료 를 받는 사람들의 기록에 대해 비밀을 지키도록 하고 있으며 학교도 이에 포함된다.

학교상담자는 교내에서 상담이나 집단 프로그램을 운영하는 과정에서 학생들에 대한 기록 또는 다른 정보가 공개되지 않도록 해야 한다. 모든 기록은 안전한 장소에 잠가서 유지되어야 하며, 다른 교육에 관련된 기록과 별도로 관리되어야 한다[18]. 기록은 학생의 서면으로 된 동의서가 없으면 공개되어서는 안 된다. 다만 학생에 대한 정보는 학생이 서면으로 동의하는 경우에는 언제든지 공개가 가능하다. 이 서면동의서에는 정보를 공개하는 프로그램의 이름, 공개된 정보를 제공받는 개인 또는 조직의 이름, 내담자 이름, 공개의 목적 또는 이유, 어떤 정보인지 그리고 어느 정보까지 공개되는지, 내담자가 어느 때라도 공개를 취소할 수 있다는 진술문, 정보공개가 종료되는 날짜·사건·조건, 내담자의 권한을 위임받은 사람의 서명, 동의 서명 날짜 등이 포함되어야 한다. 내담자에 대한 정보를 제공받는 개인 또는 조직도 정보를 외부에 공개하지 않겠다는 별도의 동의서에 서명해야 한다. 만약 내담자가 미성년자라서 부모의 동의를 요구하는 경우에는 부모 또는 보호자의 서명이 필요하다. 이 경우에는 부모 또는 보호자와 미성년자가 모두 동의서에 서명해야 한다. 그러나 미성년자가 합리적 선택을 할 수 있는 능력이 부족하지 않거나 자신의 삶을 위협하지 않는다면, 내담자와의 접촉에 대한 사실을 부모에게 공개할 수 없도록 하고 있다[1].

학생의 서면 동의 없이 정보 공개가 허용되는 경우가 몇 가지 있는데, 여러 
연구자들[1][14][18]이 제기했던 의견들을 학교상담자에게 해당되는 것 들로만 정리하면 다음과 같다.

- 학생에 대한 정보가 프로그램을 운영하는 다른 학교상담자인 경우

- 공개되는 정보에 학생이 물질 남용이나 중독이라는 사실이나 치료 프로그램에 참여하고 있다는 것이 나타나지 않는 경우

- 의료적 응급상황(물질 과다복용, 자살위협 또는 시도 등)

- 학생의 범죄와 관련된 정보

- 정보를 공개하라는 법원의 명령

- 정보가 합산된 형태이고 연구 프로젝트에 사용되는 경우

- 아동학대나 방치와 관련된 정보

그렇다면 앞에서 제시하였던 예처럼 만약 학생이 학교상담자에게 그동안 학교에서 환각제를 팔았다고 털어놓았다고 말했다면 학교상담자는 어떻게 대처하는 것이 바람직할 것인가? 이렇게 물질은 다른 범죄와 연결되는 경우가 많기 때문에 학교상담자에게는 지속적으로 갈등을 유발할 수 있다.

학생의 행위는 명백한 범법 행위이다. 물론 학교상담자는 비밀을 보장해야 할 의무가 있지만, 물질 판매가 학교 내에서 이루어졌기 때문에 비밀보장 원칙에서 제외된다[1]. 왜냐하면 범죄가 다른 사람에게 피해를 입힐 수 있기 때문에(예, 약물에 취한 상태로 오토바이 운전) 비밀보장의 원칙만 고수해서 해결될 수 없는 경우가 많다. 학교상담자는 위험성 평가와 함께 다른 사람에게 닥칠 수 있는 해에 대한 경고에 대해서도 고려해 봐야 하고, 작업동맹도 깨지지 않도록 유지해야 하기 때문에 결코 쉽지 않은 일이다. 이런 경우 학교상담자는 갈등을 해결할 수 있도록 수련감독자, 동료, 기관 등에 자문을 구하고, 내담자에게 미칠 수 있는 해를 최소화하기 위해 노력해야 한다.

만약 경찰관이 찾아와서 학생의 동의 없이 학생 기록을 열람하려 한다면 어떻게 해야 할 것인가? 이와 관련해서도 학교상담자는 경찰관이 학생 기록을 열람하도록 해서는 안 된다. 경찰관은 우선 법원으로부터 명령서를 받아야 한다. 그리고 상담 기록은 범죄 수사나 범죄자 기소에 사용되어서는 안 된다.

\section{3 다중관계}

다중관계는 상담자의 전문적 판단을 훼손시킬 수 있고, 상담자가 내담자를 부당하게 착취하거나 내담자에게 피해를 줄 수 있기 때문에 윤리강령에는 이러한 다중관계를 피하도록 명시하고 있다. 그러나 학교상담자들이 다중관계와 관련하여 윤리적 갈등에 자주 처하게 되는 이유는 학교상담자들이 학교 현장에서 상담자 역할 이외의 담임이나 교과 교사 등 다른 역할들을 수행하기 때문이다. 전문상담교사가 학교현장에 배치되어가고 있으나 이직까지 많은 학교에서 교과지도나 담임을 맡은 일반교사들이 학생들 생활지도의 상담을 책임지고 있는 우리나라 현 상황에서 다중관계를 피하는 것이 쉽지 않다.

위의 다중관계 외에도 물질남용과 관련되어서는 학교상담자가 물질남용 회복자인 경우에 많이 발생한다. 이는 한국의 상황상 회복자가 학교상담자가 되기 힘든 
상황이지만 기존의 학교상담자가 남용되었다가 회복되는 가정을 생각해볼 수는 있을 것이다. 이런 회복자들의 경우에는 자신의 회복을 위해 자조모임이나 외부의 집단상담에 참여하는 경우가 많다. 이런 상황 때문에 물질남용 학생과 다중관계의 위험을 높인다. 즉 회복자인 학교상담자 뿐 아니라 학생이 학교 밖에서 같은 AA나 NA 등의 자조모임에 참여하거나 같은 집단상담에 참여하는 경우 상담관계 뿐 아니라 자조모임이나 집단상담 동료 참가자의 역할을 하게 된다. 또한 자조모임의 경우에는 사회적 모임을 하는 경우가 많은데 이 모임에 같이 참여하게 되면 더욱 복잡한 다중관계의 위험이 생기게 된다.

\section{4 부모에 대한 의무}

모는 미성년자인 자녀들의 복지에 대한 법적인 책임을 부모가 가지고 있기 때문에 부 모들은 아동에 대한 정보를 제공받을 필요가 있으며 상담이나 개입에 대해서도 부모의 승인을 받을 필요가 있다. 그렇기 때문에 학교상담자는 부모가 내담자와의 상담 내용을 알고자 하는 경우에 이들의 요구를 거절하는 것이 쉽지 않다. 그리고 이렇게 무조건 부 모의 요구를 거절하는 것은 학생의 변화를 위해서는 부모의 협조가 필수적이기 때문에 바람직하지 않다. 이런 이유로 학교상담자들은 비밀보장 원칙과 부모의 권리를 보장해야 하는 윤리적 갈등 상황에 빠지기 쉽다. 특히 부모들의 요구가 학교상담자가 생각하는 것 보다 많은 정도일 때 고민은 깊어진다.

그렇다면 문질남용과 관련된 부모에 대한 의무와 관련된 윤리적 이슈는 무엇일까? 첫 째는 부모의 동의와 관련된 내용이다. 미국에서는 많은 주에서 부모의 동의가 없어도 미 성년자들이 물질 관련 치료를 받을 수 있도록 하고 있다[19]. 법에서 규정하고 있지 않는 경우에는 치료에 대해 동의를 할 능력이 있다고 전문가 판단하는 경우에도 가능하다. 또 한 어떤 주에서는 부모 동의 없이 치료받을 수 있는 최소 연령을 정해 놓기도 하였다. 그 최소 나이는 보통 12-14세 범위 내에서 결정되고 있다. 그럼에도 불구하고 다른 많은 주에서는 아직도 치료가 시작되기 전에 부모의 동의가 반드시 필요하다고 규정하고 있 다.

두 번째는 미성년자들이 치료를 받는다는 사실을 부모에게 알리는 것과 관련된 것이 다. 이와 관련한 미국의 상황을 먼저 살펴보면, 우선 관련 규정이 주(州)마다 다양하다. 부모에게 알려선 안 되도록 철저히 비밀을 보장하는 주가 있는가 하면, 치료를 맡은 전 문가의 판단에 따르도록 하거나, 입원해서 치료를 받는 경우에만 부모에게 알리도록 한 주도 있다. 반면 몇 개 주(예, 버지니아)에서는 학교에서 학생이 알코올이나 물질 남용 상 태인 경우 부모에게 알리도록 하는 법이 제정되어 있기도 하다.

결국 물질과 관련된 치료에 있어 부모의 동의 필요 여부나 치료 사실에 대해 지역의 부모에게 알리는 것에 대해서는 학교상담자가 속해 있는 지역의 법 규정을 따를 수밖에 없다는 것을 알 수 있다. 그러나 앞서 밝힌 바와 같이 미국에서도 통일된 한 가지 원칙 으로 규정되지 못한 실정이다. 게다가 국내에서는 물질관련 치료에 부모의 동의가 반드 시 필요하다는 또는 부모에게 알려야 한다고 규정한 법도 없다.

그렇다면 국내 학교상담자들은 학생의 물질관련 프로그램 참여시 동의서와 부모에게 알리는 문제를 어떻게 해결하면 좋을 것인가? 미국의 경우에는 법률적으로는 학부모들의 자녀에 대한 정보 요구와 정보 공개 여부 결정권에 대해 규정하고 있는 가족교육권리와 
사생활에 관한 법(Family Education Rights and Privacy Act, FERPA)과 미국교육법 Grassley 수 정조항보다 비밀보장 관련법이 우선한다. 즉, 내담 학생의 동의가 없으면 어떤 정보도 제 3 자에게 유출해선 안 되는 것이다. 그러나 임상적으로 볼 때 물질 남용 치료에 있어 전 체 가족들이 참여하지 않으면 성공하기 힘들다. 이런 임상적인 측면에서는 남용 문제를 겪고 있는 경우 부모에게 그 문제에 대해 알리고 부모와 함께 치료를 받을 수 있도록 협 력하는 것이 바람직하다. 이런 경우 학교상담자가 어떻게 해야 한다고 딱 잘라 이야기하 기는 힘들다. 학생의 처지와 학교상담자가 처한 상황마다 해결책이 다를 수 있기 때문이 다. 학교상담자는 적절히 두 가지 원칙이 모두 지켜질 수 있도록 해야 한다. 비밀보장 약 속을 지키되 부모에게 학생이 직접 알리는 방식이나, 학생의 평가 결과와 학생이 공개한 정보 이외에 것들에 대해서만 알리는 방식 등을 부모에게 알리는 것이 필요하다. 결국 부모에게 알리는 것이 반드시 필요하기는 하지만, 알리는 시점이 문제라 할 수 있다.

예를 들어 학교상담자인 진 선생님은 00 고등학교 축구부원인 기석이와 상담하던 중에 기석이가 지난 몇 년 동안 근육 강화를 위해 수퍼 비타민이라는 약을 복용해 왔다는 사 실을 알게 되었다고 하자. 축구부원 한 명이 지방의 헬스클럽에서 약을 사다가 다른 축 구부원들에게 판다는 것이었다. 기석이는 최근 스테로이드에 대한 이야기를 $\mathrm{TV}$ 에서 보고 그동안 복용해온 수퍼 비타민에 스테로이드 성분이 들어 있는 것 같다고 하였다. 기석이 는 그동안 먹어온 약 때문에 이상이 생기는 것은 아닌지 걱정이 되고 그런 일이 자신에 게 일어날 것인지 알고 싶다고 하였다(출처: Jacobs \& Hartshorne [20]). 이 사례에서 진 선생 님은 기석이의 건강 상태와 향후 부작용은 없는지, 그리고 적절한 치료 방법은 무엇인지 등에 대해 알아보기 위해선 부모님과 함께 병원을 찾도록 해야 할 것이다. 더 나아가 진 선생님은 학교 당국에 스테로이드 남용에 대한 걱정을 전하고(기수의 이름을 밝히지 않 은 채), 학부모와 학생들에게 스테로이드 사용의 위험성에 대해 경각심을 일깨울 방법을 고안할 필요가 있다.

\section{5 의뢰 (Referral)}

학교상담자가 물질 오용에 대한 훈련이 되어 있질 않거나, 교내에 물질 관련 프로그램 을 운영하기 어려운 경우에는 자조집단이나 외부 기관에 의뢰할 필요가 있다. 이렇게 의 뢰하는 과정에서 학교상담자가 유념해야 할 것이 학생의 동의(consent)를 획득하는 것이 다. 이 과정에서는 부모의 동의보다도 학생 본인의 동의가 더욱 중요하다.

\section{5. 결론}

이 연구에서는 학교상담자가 물질 남용 예방과 상담에서 고려해야 할 윤리적 요소는 무엇인지를 고찰하였다. 우선 학교상담자들이 물질 남용을 예방하기 위한 활동에서 유의 해야 할 중요한 윤리적 요소인 비밀보장과 관련된 것은 예방활동에 참여한 학생이 물질 사용이나 남용한 사실이 알려지지 않도록 유의해야 하는 것이다. 특히 그 학교에 물질 문제와 관련된 프로그램만 하는 경우에는 학생들의 참여 사실에 대한 정보에 대해 비밀 을 보장해야 할 필요가 있다. 그리고 사정과 관련된 활동을 시작하면서부터 학교상담자 의 비밀보장의 의무가 본격적으로 시작된다는 것이었다. 그리고 상담 장면에서는 학생들 의 기록이나 여타 정보가 공개되지 않도록 해야 하며, 학교상담자는 비밀보장의 예외 상 
황에 대해 잘 인지하고 있어야 한다. 특히 물질 남용은 범죄와 관련된 경우가 많기 때문 에 이에 대해서는 학교상담자들이 갈등을 일으킬 가능성이 많다. 또한 학교상담자는 부 모에 대한 의무도 가지는데 이때 중요한 것은 비밀보장 약속이 지켜지도록 하면서도 부 모도 학생의 상태에 대해 알 수 있도록 하기 위한 다양한 방법을 고안해야 할 필요가 있 다. 마지막으로 의뢰 장면에서는 학생의 동의를 획득하는 것이 무엇보다 중요하다.

이 연구에서는 우리나라에서 중독 상담 윤리에 대한 연구가 부족한 상황에서 학교 장면에서 물질 남용을 예방하고 상담하는 데 있어서 학교상담자들이 고려해야 할 윤리가 무엇인지를 고찰하였다는 점에서 의미가 있다. 다만 현재 학교에서 일어날 수 있는 상황에만 초점을 두어 고찰하였기 때문에 중독 상담 윤리에서 흔히 다뤄지는 다양한 주제들(예, 경계 또는 다중관계, 자율성 존중, 해(害) 줄이기, 상담자 역량)에 대해서는 자세하게 다루지 못했다. 아직까지 국내 학생들의 물질남용 심각성이 외국에 비해 덜한 점과 이런 주제들은 국내 성인들을 대상으로 한 중독 상담 과정에서 나타날 수 있는 윤리적 고려와 차별되는 점이라 볼 수 있기 때문이다. 그러나 향후 학교 내에서의 물질남용의 문제가 더욱 심각해지고 여러 윤리적 고려 상황들이 생긴다면 더욱 다양한 윤리 주제들에 대한 심도 있는 고찰이 필요할 것이다.

\section{References}

[1] G. L. Fisher, T. C. Harrison, Substance abuse: Information for school counselors, social workers, therapists and counselors (6th ed.), Pearson, (2017)

[2] Substance abuse, Retrieved from http://www.who.int/topics/substance_abuse/en/ on 2021, World Health Organization, Jan 27, (2021)

[3] R. M. Garman, This is your brain on drugs: SUD, cognitive impairment, and mental health disorders, Journal of Addiction Research \& Therapy, (2013), Vol.4, No.1, p.141, DOI:10.4172/2155-6105.1000141

[4] D. J. DeWit, E. M. Adlaf, D. R. Offord, A. C. Ogborne, Age at first alcohol use: A risk factor for the development of alcohol disorders, American Journal of Psychiatry, (2000), Vol.157, No.5, pp.745-750, DOI: 10.1176/appi.ajp.157.5.745

[5] D. A. Brent, Risk factors for adolescent suicide and suicidal behavior: Mental and substance abuse disorders, family environmental factors, and life stress. Suicide and Life-Threatening Behavior, (1995), Vol.25, Suppl, pp.52-63, https://doi.org/10.1111/j.1943-278X.1995.tb00490.x

[6] K. Fox, J. C. Merrill, H. H. Chang, J. A. Califano, Estimating the costs of substance abuse to the Medicaid hospital care program, American Journal of Public Health, (1995), Vol.85, No.1, pp.48-54, DOI: 10.2105/ajph.85.1.48

[7] J. R. Kang, J. Y. Lee, H. D. Son, An analysis of the school counselor's ethical dilemmas and coping strategies, The Korea Journal of Youth Counseling, (2007), Vol.15, No.1, pp.17-27, http://dx.doi.org/10.35151/kyci.2007.15.1.002

[8] R. R. Cottone, V. M. Tarvydas, Counseling ethics and decision making (3rd ed.), Pearson, (2006)

[9] R. M. House, R. L. Hayes, School counselors: Becoming key players in school reform, Professional School Counseling, (2002), Vol.5, pp.249-256.

[10] National Association of Alcoholism and Drug Abuse Counselors, NAADAC Code of Ethics, https://www.naadac.org/code-of-ethics, (2004)

[11] D. C. Gottfredson, D. B. Wilson, Characteristics of effective school-based substance abuse prevention, Prevention Science, (2003), Vol.4, No.1, pp.27-38, doi: 10.1023/a:1021782710278

[12] K. B. Kim, A study of early detection of adolescent drug user`s \& adolescent drug addicts, Korean Journal of Youth 
Studies, (1997), Vol.4, pp.209-223.

[13] S. V. Cleave, W. Byrd, K. Revell, Counseling for substance abuse and addiction (J. S. Yoon Translation), Duranno, Seoul, (1997)

[14] M. K. Brooks, Legal Issues for Alcohol and Other Drug Use Prevention and Treatment Programs Serving High-Risk Youth, US Department of Health and Human Services, Public Health Service, Alcohol, Drug Abuse, and Mental Health Administration, Office for Substance Abuse Prevention, (OSAP Technical Report 2), (1990)

[15] K. M. Coll, Legal challenges in secondary prevention programming for students with substance abuse problems, The School Counselor, (1995), Vol.43, No.1, pp.35-41.

[16] J. H. Kim, Theory and practice of guiding youth in crisis: For counselors, teachers, psychologists, and interpersonal service professionals, Minjisa, (2001)

[17] R. M. Hubert, L. T. Freeman, Report of the ACA ethics committee: 2002-2003, Journal of Counseling \& Development, (2004), Vol.82, No.2, pp.248-251, https://doi.org/10.1002/j.1556-6678.2004.tb00308.x

[18] K. A. Sealander, V. L. Schwiebert, T. A. Oren, J. L. Weekley, Confidentiality and the law, Professional School Counseling, (1999), Vol.3, No.2, pp.122-127.

[19] B. A. Weiner, R. M. Wettstein, Competency and guardianship, Legal Issues in Mental Health Care, Springer, (2013), pp.273-308.

[20] S. Jacob, D. M. Decker, T. S. Hartshorne, Ethics and Law for School Psychologists (4th ed.), John Wiley and Sons, (2003) 